\title{
Urgences
}

\section{Le doux privilège}

\section{Sonya Anguelova}

Numéro 2, 3e trimestre 1981

URI : https://id.erudit.org/iderudit/025022ar

DOI : https://doi.org/10.7202/025022ar

Aller au sommaire du numéro

Éditeur(s)

Urgences

ISSN

0226-9554 (imprimé)

1927-3924 (numérique)

Découvrir la revue

Citer ce document

Anguelova, S. (1981). Le doux privilège. Urgences, (2), 15-19.

https://doi.org/10.7202/025022ar

Ce document est protégé par la loi sur le droit d'auteur. L'utilisation des services d'Érudit (y compris la reproduction) est assujettie à sa politique d'utilisation que vous pouvez consulter en ligne.

https://apropos.erudit.org/fr/usagers/politique-dutilisation/
Cet article est diffusé et préservé par Érudit.

Érudit est un consortium interuniversitaire sans but lucratif composé de l'Université de Montréal, l'Université Laval et l'Université du Québec à Montréal. Il a pour mission la promotion et la valorisation de la recherche. https://www.erudit.org/fr/ 
SONIA ANGUELOUA

\section{Le doux privilège}




\section{LE DOUX PRIVILÈGE}

0 , le doux privilège de pouvoir disposer de tout son temps

0 , le doux privilège de pouvoir dire sans crainte ses pensées

0 , le doux privilège de se nourrir de belle musique

De respirer l'air du printemps sans être derrière les barreaux

Sans vivre la violence et la torture

Douces heures de paix

Douces heures d'avant la nuit sur une rhapsody in blue

Si! Je crois dans les pouvoirs de la pensée

J'ai envie d'envoyer à tous les prisonniers coupables d'avoir pensé à leur liberté de parole

Coupables d'avoir cru dans la hauteur de l'homme, dans sa divinité

Leur envoyer à travers mon corps et mon coeur cette belle rhapsody in blue

Quelques instants de douceur, de calme, d'amitié

Dimiter Kolev, où es-tu en ce moment,

Dedans les murs, dehors ou peut-être mort

Ecrire en termes courtois pour demander instamment la libération de Dimitri Kolev à Monsieur Todor Jivkov,

Président du Conseil d'État, Sofia, Bulgarie

Bulgarie - mon beau pays

On a mis des murailles de Chine autour de toi

Pour empêcher tes citoyens de sortir

Mon beau pays

Tu n'as sûrement pas voulu que du monde pourrisse dans tes prisons

Pour avoir voulu voir comment c'était ailleurs.

Ecrire en termes courtois à un premier ministre, car on ne peut pas l'accuser

D'incarcérer au nom de la patrie

Dimiter Kolev, coupable de vouloir quitter son pays sans autorisation

"Pourquoi vouloir sortir, on est bien mieux chez-soi

Les dangers en dehors du pays sont grands

Et notre peuple si petit, gardons-nous unis"

Mon beau pays, tu me fais penser à un vase, à une boite depuis longtemps fermée, scellée, pauvres gens, ils sont en train de mourir asphyxiés dedans

Je ne peux pas rester à écouter et à regarder sans en parler

Ici je peux le dire

Si seulement j'avais des ailes... 
J'effacerais de la Terre entière ce goût de sang et de torture Je croyais que les tortures avaient depuis longtemps passé dans l'histoire

Mais comment effacer les souvenirs des têtes des bourreaux? 


\section{LES MOTS MUTILES}

Les mots roulent dans ma bouche

Ma langue se tord et ne veut pas les dire

J'ouvre la bouche et seul l'air la remplit

J'peux pas avaler mes mots qui roulent, roulent en-dessous de ma langue

$\mathrm{Au}$ fond de ma gorge

Mes lèvres s'ouvrent et ma langue se tord

Quelle langue je parle?

Ce n'est que des sons

$000000000000000 \mathrm{H}, \mathrm{OH}$

Je roule des "oh... oh... oh..."

Je roule des "uh... uh... uh..."

Quelle langue je parle?

Je ne suis que des "oh"

Je ne suis que des "uh"

Roulants Tordants Ouvrants

Ma langue n'est pas à l'aise dans ces mots

Elle ne veut pas les "dire"

Faut que je crie

Faut que je crie avec ma peau, avec mes poumons

Faut que mes cellules ensemble crient

Que mon corps entier parle, se torde, fourmille des mots,

Des gestes, des lumières cachées, des tendresses masquées,

De la colère tamisée

Faut que ma langue obéisse aux cris de mes cellules,

À la vague qui noie mon coeur

Je roule, roule les sons dans ma bouche longtemps

Des tambours de ma colère

Des tambours de ma misère,

Je roule des $\mathrm{OH}$..... oh..... oh.....

Longtemps..... longtemps..... longtemps..... 


\section{À MA MÈRE}

Par les fils de laine de ton tricot

Je remonte dès aujourd'hui à toi, à ton coeur

Les mots se taisent dans ta bouche

Tes yeux se ferment et regardent au-dedans de toi

Les mots se taisent dans ta bouche

Les mailles que tes aiguilles font

Les enferment dans leur circonférence

Tes mots ont des menottes

Sont enfermés à jamais

Et si je veux te connaitre, si je veux savoir ce qui fut "hier" Le "passé" de toi

Il me faut défaire tous ces bas, gilets, tuques et mitaines

Il me faut libérer tous ces mots et regards

Toutes tes peines enfermées

Les livrer...

Pour retrouver les fils d'or de ton coeur. 